\title{
Refredament magnètic: ordre i desordre d'imants atòmics
}

\author{
Xavier Bohigas \\ Departament de Física i Enginyeria Nuclear, Universitat Politècnica de Catalunya
}

S'ha comprovat que la refrigeració magnètica que utilitza un sistema magnètic és energèticament eficient i competitiva amb la tecnologia refrigerant basada en la compressió de gasos en el rang de temperatures proper a la temperatura ambient. En aquest article se'n mostren el fonaments.

Paraules clau: entropia, refrigeració magnètica, efecte magnetocalòric, perovskites

\section{Per tenir l'aigua ben fresqueta}

Si volem refredar una ampolla d'aigua, tenim diverses possibilitats. La majoria de la gent la posa dins de la nevera, però també la podem refredar introduint-la en una galleda que contingui un líquid més fred que la nostra ampolla. Això ho sap molt bé la gent de pagès quan, a l'estiu, posen els melons o les síndries a refrescar submergides en l'aigua del pou. Aquest també és el sistema utilitzat en els restaurants per refredar les ampolles de vi blanc: l'ampolla es col-loca dins d'una galleda plena de gel i aigua, i d'aquesta manera el bany fred que envolta l'ampolla va refredant lentament el vi. No hem de pensar que aquest mètode de refrigeració mitjançant un bany tèrmic està reservat únicament a utilitzacions casolanes; al contrari, és el sistema habitual de refredament en dispositius científics de tecnologia avançada que treballen a molt baixa temperatura. El líquid refrigerant, en comptes d'aigua amb glaçons, és nitrogen líquid amb el qual es poden assolir temperatures al voltant de $77 \mathrm{~K}(-196$ $\left.{ }^{\circ} \mathrm{C}\right)$. Per aconseguir temperatures de l'ordre de $4 \mathrm{~K}$ $\left(-269^{\circ} \mathrm{C}\right)$ es fa servir heli líquid. En tots aquests casos, el refredament d'un cos calent es produeix a través del contacte amb una font freda.

\section{Refredar amb màquines}

Ara bé, en la majoria de casos de la nostra vida quotidiana, no disposem d'una font freda, sinó que l'hem de generar a partir d'aparells específics per fer-ho, com ara els frigorífics domèstics, els congeladors o els aires condicionats. Esquemàticament, el seu funcionament consisteix en absorbir calor d'una font freda (l'interior del nostre frigorífic) i transportar aquesta calor fins a una font calenta (aire de l'habitació on tenim el frigorífic), on es dissiparà. Per realitzar aquest procés necessitem l'aportació energètica que ens subministra la connexió del frigorífic a la xarxa elèctrica. Això permet fer funcionar tant una bomba que fa circular el fluid que absorbeix la calor de la font freda i la cedeix a la font calenta com un compressor que el sotmet a processos cíclics de compressió i descompressió. Aquest fluid fa de transmissor de calor entre la font freda i la font calenta. Fins fa poc aquest fluid eren els coneguts CFC, compostos molt perjudicials per al manteniment de la capa d'ozó, que protegeix la superfície terrestre de la radiació ultraviolada provinent del Sol.

Una possible alternativa a la refrigeració convencional de gas és la refrigeració magnètica.

La refrigeració magnètica és una tècnica,desenvolupada per primera vegada el 1933 per W. F. Giauque i D. P. MacDougall amb la qual s'aconsegueixen temperatures de l'ordre del mil-likelvin. L'aparell original era un instrument de desmagnetització adiabàtica on es refredava una sal paramagnètica a molt baixa temperatura mitjançant la variació d'un camp magnètic (més avall expliquem els seus fonaments).

Aquest mètode s'ha mantingut com una tècnica de refrigeració però és utilitzable exclusivament a molt baixes temperatures ja que fins ara no es dis- 
posava dels materials adequats per utilitzar la refrigeració magnètica a temperatures més altes.

\section{Comportament dels materials magnètics}

Abans de descriure els detalls de la refrigeració magnètica hem de fer un parèntesi per saber alguna cosa més sobre els materials magnètics.

Des del punt de vista de les seves propietats magnètiques els materials es classifiquen -de forma simplificada- en diamagnètics, paramagnètics $i$ ferromagnètics. Per a les aplicacions en el refredament magnètic únicament són interessants els materials paramagnètics i ferromagnètics.

Els materials ferromagnètics són atrets fortament pels imants; els més coneguts són el ferro i el níquel. Els materials paramagnètics, com l'alumini, també són atrets cap a les regions de camp magnètic intens, però amb una intensitat molt menor que els materials ferromagnètics.

Aquests diferents comportaments es poden explicar a partir de l'estructura interna de la matèria, fixant-nos en el comportament dels àtoms i en el moviment dels electrons que hi orbiten al seu voltant. Segons aquest model, els electrons són partícules que giren sobre si mateixos $i$, alhora, giren al voltant del nucli de l'àtom. El moment magnètic expressa la mesura de la intensitat total amb que els electrons realitzen aquests girs, tant sobre si mateixos (espin) com al voltant del nucli (moment orbital). El moment magnètic de cada àtom porta associada una direcció, que ve determinada per l'eix de rotació al voltant del qual gira l'electró. És a dir, que cada àtom, al tenir electrons donant voltes al seu voltant, es comporta com un petit imant que té una direcció determinada, i per tant, un petit pol nord i un petit pol sud. La magnetització (també se'n diu imantació) d'un material és la suma total de moments magnètics per unitat de volum.

Sabem que els materials que tenen un comportament paramagnètic estan constituïts per àtoms que tenen un moment magnètic total no nul. En canvi, el moment magnètic dels àtoms dels materials diamagnètics és nul. Podem imaginar, doncs, cada un dels àtoms dels materials paramagnètics com un petit imant, amb el seu pol nord i el seu pol sud, com una brúixola.

Si no hi ha un camp magnètic extern, en un material paramagnètic tots els moments magnètics atòmics (els petits imants atòmics) estan orientats en totes les direccions possibles: estan desordenats, tal i com es representa a la fig. 1a. Aquest desordre està afavorit per l'agitació tèrmica que fa oscilllar contínuament cada un dels imants atòmics. Així, des del punt de vista macroscòpic, el material presentarà una magnetització total igual a zero, ja que la suma dels moments atòmics dóna zero.

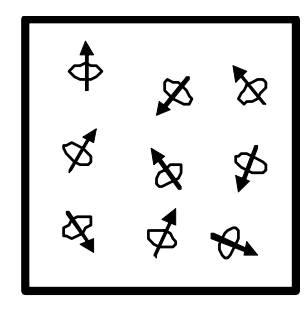

a. Material paramagnètic en absència de camp magnètic.

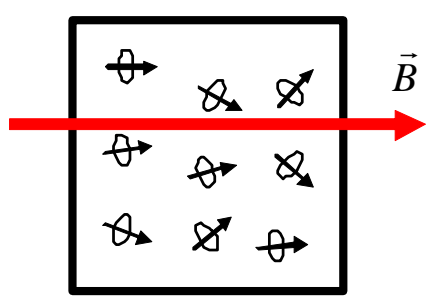

b. Material paramagnètic sota l'acció d'un camp magnètic aplicat.

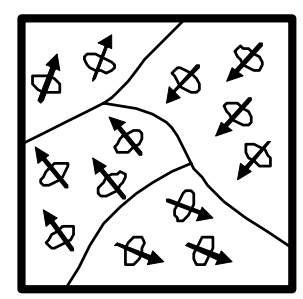

c. Material ferromagnètic en absència de camp magnètic.

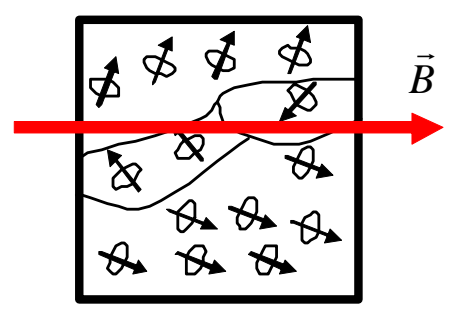

d. Material ferromagnètic sota l'acció d'un camp magnètic aplicat.

Figura 1. Representació esquemàtica de l'orientació del moments magnètics atòmics. 
Si sotmetem el nostre material paramagnètic a l'acció d'un camp magnètic dèbil, la interacció entre aquest camp magnètic aplicat i els moments magnètics atòmics del material tendirà a orientar-los en la direcció del camp (fig. 1b). De la mateixa manera que la brúixola s'orienta en la direcció del camp magnètic terrestre, si la deixem girar lliurement. Així, el material tindrà una magnetització no nul·la (en aquest cas induïda pel camp magnètic aplicat). Si no tinguéssim en compte l'agitació tèrmica, l'alineació dels imants atòmics seria total: tots els moments magnètics estarien orientats en la mateixa direcció del camp. Però l'agitació tèrmica és la responsable que l'alineació dels moments magnètics atòmics no sigui completa. I quan retirem el camp magnètic aplicat, recuperem la situació inicial.

En els materials ferromagnètics la situació és una mica més complexa. El moment magnètic dels àtoms dels materials ferromagnètics també és diferent de zero, però existeix interacció entre els distints àtoms propers, de manera que es formen regions dins del material -aquestes regions s'anomenen dominis magnètics i també dominis de Weiss-. En cada una d'aquestes regions tots els imants atòmics estan orientats en la mateixa direcció, que és diferent a la direcció dels moments magnètics en regions veïnes (fig. 1c). En aplicar un camp magnètic sobre un material ferromagnètic creixen els dominis magnètics que tenen la magnetització en la direcció del camp aplicat (fig. 1d). Aquest augment de volum dels dominis fa que la magnetització del material, des del punt de vista macroscòpic, sigui diferent de zero. En retirar el camp magnètic aplicat, el moviment de les parets dels dominis queda frenat per la interacció amb els dominis veïns i no recuperem la distribució de dominis de la situació inicial. El material quedarà amb una magnetització romanent, direm que s'ha magnetitzat. Tenim un imant!

\section{Què és la refrigeració magnètica}

Tornem a la refrigeració magnètica. Hem vist que quan s'aplica un camp magnètic a un material magnètic, els seus moments magnètics tendeixen a orientar-se en la mateixa direcció del camp aplicat, s'aconsegueix un estat més ordenat $i$, per tant, d'entropia menor. El concepte d'entropia està relacionat amb el concepte de probabilitat termodinàmica, és a dir amb el nombre dels distints estats microscòpics d'un sistema que donen lloc al mateix estat determinable macroscòpicament. És a dir, indica les maneres diferents amb què podem disposar les coses internament de manera que externament sembli el mateix. Per això s'associa l'entro- pia amb el grau de desordre d'un sistema físic. Com més desordenat estigui el sistema, més gran serà la seva entropia. Un plat trencat té una entropia més gran que el plat sencer.

La termodinàmica ens ensenya que quan un sistema absorbeix calor, la seva entropia augmenta. Per tant, la variació d'entropia està relacionada amb l'augment de temperatura del sistema.

En un sistema magnètic coexisteixen l'entropia magnètica, que ens indica el grau d'ordenament dels moments magnètics que constitueixen el material, i l'entropia tèrmica, relacionada amb l'agitació tèrmica de les molècules que constitueixen el material i, per tant, amb la seva temperatura.

Així doncs, si apliquem un camp magnètic a un sistema magnètic produïm una disminució de la seva entropia magnètica. Però si el sistema està aïllat, és a dir que no pot intercanviar calor amb el medi que l'envolta, la disminució d'entropia magnètica provocarà un augment de l'entropia tèrmica en la mateixa quantitat, ja que com que el sistema està aïllat, l'entropia total no pot variar. L'augment d'entropia tèrmica produirà un augment de temperatura del material. Es coneix com a efecte magnetocalòric la variació de temperatura produïda per la variació del camp magnètic aplicat sobre un material magnètic.

Per tant, aplicant un camp magnètic a un sistema magnètic aïllat produïm un augment de la seva temperatura. El procés invers també és vàlid, quan eliminem el camp magnètic, el sistema es refreda, si es manté aïllat de l'exterior.

\section{La nevera magnètica}

Si volem refredar un recipient (l'interior del frigorífic magnètic) podem fer el que expliquem a continuació. Situem un material magnètic sotmès a un camp magnètic dins del recipient que volem refredar. Eliminem el camp magnètic i el material magnètic es refreda, per tant absorbirà calor del seu entorn, és a dir de l'interior del recipient que volem refredar. A continuació extraiem el material magnètic del recipient perquè dissipi la calor absorbida a l'entorn (a l'aire que envolta la nevera). D'aquesta manera "traiem" calor (energia a través de calor) del recipient. Realitzant reiteradament aquest procés podem refredar l'interior del recipient.

El procés del refredament magnètic és similar al procés de refredament del nostre frigorífic domèstic, però en comptes de processos de compressió i descompressió, s'hi realitzen processos cíclics de magnetització i desmagnetització. I en comptes d'utilitzar gasos refrigerants utilitzem materials magnètics per extreure energia mitjançant calor de l'inte- 
rior de la nevera i reduir així la seva temperatura. El gran canvi d'entropia inherent als fenòmens d'ordenació magnètica, així com la reversibilitat dels processos d'ordenació i desordenació, fan que la refrigeració magnètica es pugui utilitzar com a tècnica refrigerant a alta temperatura.

Tinguem en compte que la refrigeració magnètica, segons s'ha deduït a partir de models teòrics, és competitiva amb la refrigeració de gas; amb els refrigerants magnètics es pot obtenir un canvi d'entropia entre 40 i 200 vegades més gran que l'obtingut amb refrigerants de gas.

\section{Quins materials magnètics són els idonis?}

El problema de la refrigeració magnètica a temperatura ambient està centrat en trobar els materials que presentin una variació gran de la magnetització en aquest rang de temperatures. Des de fa anys s'estan investigant les propietats magnètiques de molts materials amb l'objectiu de trobar els idonis per incorporar-los a cicles refrigerants magnètics.

Sabem que el canvi entròpic produït en un material magnètic a causa d'una variació de camp magnètic depèn de la variació de la magnetització amb la temperatura, segons l'expressió

$$
\Delta S_{\text {mag }}=\int_{0}^{H}\left(\frac{\partial M}{\partial T}\right)_{H} d H
$$

Matemàticament diem que el canvi entròpic depèn de la derivada de la magnetització respecte de la temperatura.

Així doncs, per tenir canvis entròpics grans, i per tant variacions de temperatura grans, serà necessari utilitzar materials magnètics tals que la magnetització presenti una variació molt gran amb la temperatura.

Analitzarem algunes dades experimentals amb l'ajuda de l'expressió anterior. A la fig. 2 hem representat la magnetització d'una mostra d'una substància, $\mathrm{Ba}_{0,6} \mathrm{Yb}_{0,4} \mathrm{~F}_{2,4}$, sota l'acció d'un camp magnètic feble, en funció de la temperatura. Es veu clarament que la magnetització varia molt ràpidament a baixes temperatures (la derivada de la magnetització respecte de la temperatura és gran) però que ho fa molt poc a temperatures altes. Aquest és el comportament típic dels materials paramagnètics. Així, els materials la magnetització dels quals té un comportament similar al representat a la fig. 2, es poden utilitzar com a refrigerants magnètics a molt baixa temperatura -com els utilitzats en l'aparell dissenyat per Giauque i MacDougall-, però no se- ran operatius a alta temperatura. (Les dades experimentals de les figures 2, 3 i 4 han estat obtingudes per l'autor).

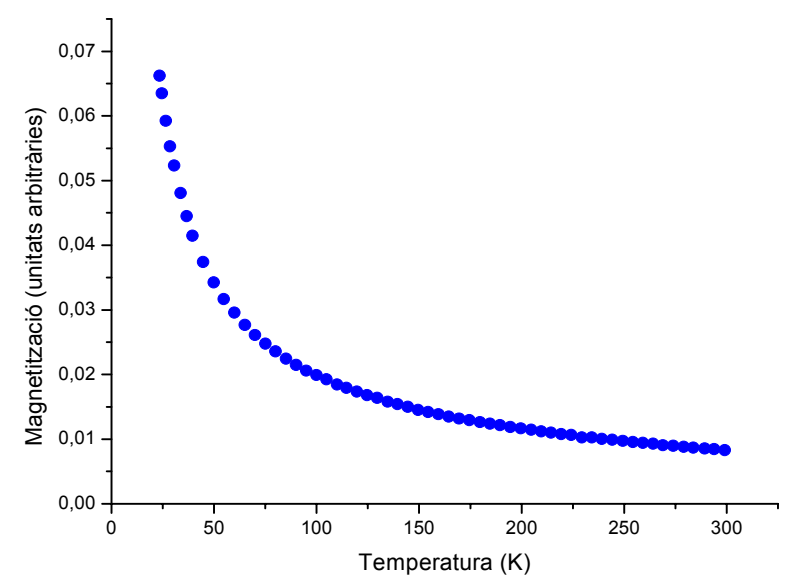

Figura 2. Magnetització en funció de la temperatura d'una mostra paramagnètica de $\mathrm{Ba}_{0,6} \mathrm{Yb}_{0,4} \mathrm{~F}_{2,4}$ sota l'acció d'un camp magnètic feble. La variació de la magnetització és gran a baixes temperatures, però no varia gaire a temperatures altes.

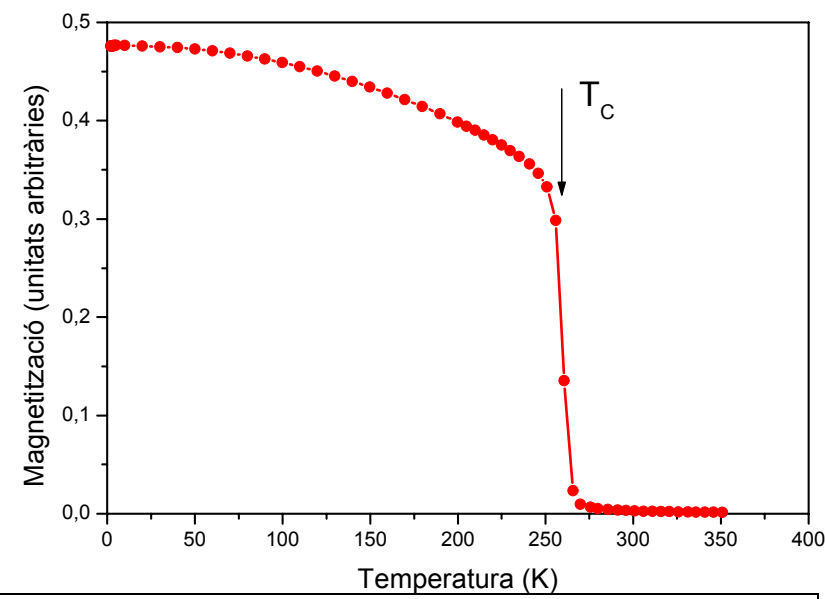

Figura 3. Magnetització en funció de la temperatura d'una mostra de $\mathrm{La}_{0,65} \mathrm{Ca}_{0,35} \mathrm{MnO}_{3}$ sota l'acció d'un camp magnètic feble. $A$ la temperatura $T_{C}$ hi ha una transició de fase magnètica. Per temperatures menors a la $T_{C}$ el material té comportament ferromagnètic, mentre que per sobre de $T_{C}$ té comportament paramagnètic.

Els materials ferromagnètics presenten un comportament ben diferent. La magnetització no varia gaire a baixes temperatures, vegeu la fig. 3 on hem representat la magnetització en funció de la temperatura d'una mostra de $\mathrm{La}_{0,65} \mathrm{Ca}_{0,35} \mathrm{MnO}_{3}$. Tampoc varia apreciablement a temperatures altes. Però es veu ben clar que la magnetització disminueix dràsticament a una temperatura a prop de $260 \mathrm{~K}$. 
La temperatura on es produeix aquesta disminució dràstica de la magnetització s'anomena temperatura de Curie. Això vol dir que el canvi entròpic magnètic associat a un procés de magnetització o de desmagnetització d'aquest material a una temperatura de $260 \mathrm{~K}$ seria molt gran, tal i com ens indica la fórmula (1). I això és, justament, el que es comprova experimentalment, tal i com es pot veure a la fig. 4, on hem representat el component magnètic del canvi entròpic d'aquest material en funció de la temperatura, i que evidencia que aquest canvi presenta un valor màxim una mica per sota de $260 \mathrm{~K}$.

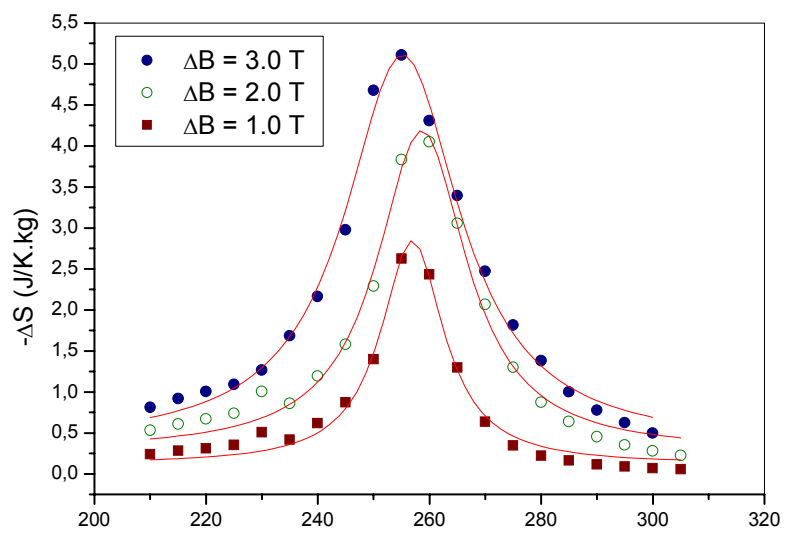

Figura 4. Canvi entròpic produït en una mostra de $\mathrm{La}_{0,65} \mathrm{Ca}_{0,35} \mathrm{MnO}_{3}$ en aplicar-hi una variació de camp magnètic de 1,0 T (घ), 2,0 T (O) i 3,0 T (•).

Els millors materials trobats fins avui que presenten un canvi entròpic gran són aquells que tenen una estructura de perovskita. La perovskita és un mineral de fórmula $\mathrm{CaTiO}_{3}$. Per substitució del Ti pel Fe, Mn o Co obtenim altres òxids amb unes propietats físiques molt interessants.

El fet més destacable, a més del gran canvi entròpic que presenten aquests materials amb estructura de perovskita, és que variant els elements que substitueixen el $\mathrm{Ca}$ i el $\mathrm{Ti}$, obtenim una família de materials amb valors de la temperatura de Curie compresos entre la temperatura de l'heli líquid i la temperatura ambient. Això els fa especialment interessants per a ser utilitzats com a materials refrigerants magnètics.

\section{Ja existeix la nevera magnètica?}

Durant les últimes dècades s'han construït diferents aparells refrigerants basats en l'efecte magnetocalòric, operatius a temperatures de treball molt baixes. Estudis realitzats recentment proven que la refrigeració magnètica que utilitza un sistema regenerador magnètic és energèticament efi- cient i competitiva amb la tecnologia refrigerant basada en la compressió de gasos en el rang de temperatures proper a la temperatura ambient.

En els últims anys s'han realitzat diversos prototips d'aparells magnètics refrigerants operatius a temperatura ambient. La majoria d'ells utilitzen gadolini com a material refrigerant que es fa passar per una regió on hi ha un camp magnètic. A la fig. 5 mostrem una fotografia d'un d'aquests prototips.

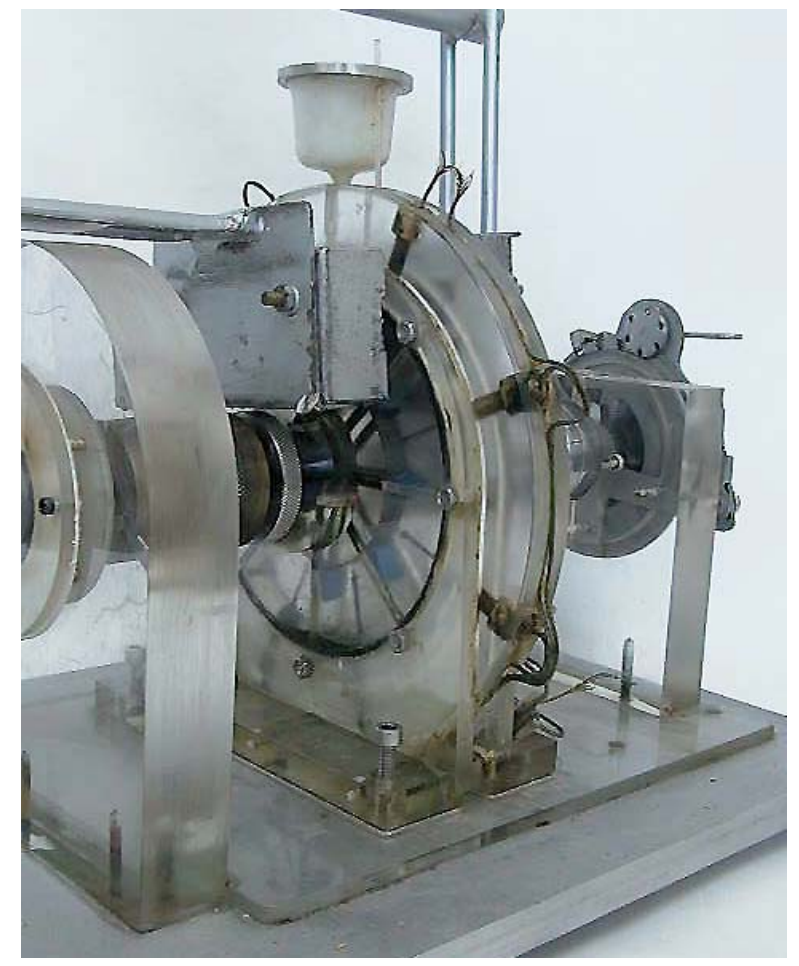

Figura 5. Un dels pocs prototipus de refrigerador magnètic que s'han construït.

Tots aquests aparells són capaços de refrigerar a temperatura ambient, si bé amb una eficiència relativament petita comparada amb els aparells de refrigeració convencional. El gadolini és el material que presenta un canvi entròpic més gran a temperatura ambient, si bé té l'inconvenient del seu alt preu. Els avenços en l'estudi de les perovskites semblen indicar que aquests materials poden ser uns bons substituts del gadolini, amb una reducció petita de l'eficiència de l'aparell.

Tant els processos físics que intervenen en la refrigeració magnètica com les propietats dels materials susceptibles de ser usats com a refrigerants magnètics, són relativament ben coneguts. Així doncs, sembla evident que cal una estreta col-laboració entre els investigadors de la ciència bàsica $i$ els enginyers per desenvolupar dispositius tecnològicament més avançats, en els quals s'hagi millorat el rendiment d'aquests primers prototips. D'a- 
questa manera serà possible fer operativa la refrigeració magnètica a temperatura ambient.

\section{Bibliografia}

M. Tishin i Y. I. Spichkin (2003). The Magnetocaloric Effect and its Applications. Institute of Physics Publishing. Bristol and Philadelfia.

Manh-Huong Phan i Seong-Cho Yu (2007). "Review of the magnetocaloric effect in manganite materials". Journal of Magnetism and Magnetic Materials 308, 325-340.
X. Bohigas, E. Molins, A. Roig, J. Tejada i X.X. Zhang (2000). "Room-Temperature Magnetic Refrigerator Using Permanent Magnets". IEEE Transactions on Magnetics 36, 538-544.

X. Bohigas, E. del Barco, J. Tejada, X.X. Zhang i M. Sales (1998). "Tunable magnetocaloric effect in ceramic perovskites". Applied Physics Letters 73, 390-392.

BF Yu, Q Gao, B Zhang, XZ Meng, i Z Chen (2003). "Review on research of room temperature magnetic refrigeration". International Journal of Refrigeration, 26, 622-636. 